\title{
PERANCANGAN SISTEM MANAJEMEN PERSEDIAAN BARANG DAGANG BERBASIS WEB BAGI BISNIS RETAIL
}

\author{
Nurwahyuningsih ${ }^{1}$, Nurul Arifin ${ }^{2}$, Risna Destiana Sari ${ }^{3}$, Vicky Nur Fauzi $^{4}$ \\ Program Studi Manajemen Keuangan Syariah ${ }^{1,2,3}$, Program Studi Teknik Informatika ${ }^{4}$ \\ UIN Sunan Gunung Djati Bandung ${ }^{1,2,3}$ \\ Sekolah Tinggi Teknologi Bandung ${ }^{3}$ \\ kenur211@gmail.com¹, arifinurul@gmail.com², risnadestiana9g@gmail.com ${ }^{2}$, nurfauzyvicky@gmail.com ${ }^{3}$
}

\begin{abstract}
Abstrak
Dewasa ini, prospek bisnis retail yang cukup menjamin, hal ini tentunya akan mengakibatkan permintaan yang meningkat. Namun disamping itu, jumlah pesaing pun semakin menjamur. Untuk mampu bersaing dan menjaga eksistensinya dengan kemampuan menyediakan produk yang dicari oleh konsumen karena pada umumnya produk yang dipasarkan oleh bisnis retail ini memiliki kemiripan atau bahkan sama persis. Jika konsumen tidak menemukan barang yang dicari dengan alasan ketidaktersediaan persediaan maka akan mengurangi citra pada toko tersebut. Pemasalahan yang sering muncul pada bisnis retail kecil ialah kurangnya kualitas pengelolaan persediaan yang mengakibatkan penumpukan barang dagang yang tak terjual. Hal ini terjadi karena sistem pengelolaan persediaan dilakukan secara konvensional dimana pemeriksaan ketersediaan barang persediaan dilakukan berdasarkan perkiraan atau ingatan saja tanpa melakukan perhitungan secara akurat. Hal ini tentunya akan merugikan bagi pemilik karena dapat menyebabkan penumpukan persediaan yang beresiko mengalami kerusakan barang dan tentunya akan menurunkan citra toko karena tidak mampu menyediakan kebutuhan konsumen karena ketidaktelitian dalam mengelola persediaan. Berdasarkan beberapa kasus yang meliputi masalah biaya, penumpukan barang hingga kehilangan konsumen, maka perlu adanya sistem manajemen persediaan barang. Dalam penelitian ini, penulis merancang sistem manajemen persediaan yang sesuai dengan kebutuhan sistem manajemen bisnis retail Muslimah Hijab. Perancangan ini meliputi tahap perencanaan dengan pembuatan Use case serta merancang tampilan sistem yang meliputi menu stock barang, menu barang masuk serta menu barang keluar. Sistem ini dirangcang dengan pengembangan perangkat lunak menggunakan PHP (Hypertext Preprocessor).
\end{abstract}

Kata kunci : Sistem, Manajemen Persediaaan, Retail, Website.

\begin{abstract}
Currently, the prospect of a fairly guaranteed retail business will certainly increase demand. But in addition, the number of competitors is increasingly mushrooming. To be able to compete and maintain its existence with the ability to provide products sought by consumers because in general, the products marketed by retail businesses have similarities or even the same. If consumers do not find the item they are looking for because the item is not available, it will reduce the image of the store. Errors that often arise in small retail businesses are poor inventory management, resulting in a buildup of unsold merchandise. This happens because the inventory management system is carried out conventionally where the examination of the availability of inventory goods is done based on estimates or memories alone without doing accurate calculations. This will be detrimental to the owner because can cause a buildup of inventory that is at risk of damage to goods and will reduce the image of the store because it is not able to provide consumer needs due to inaccuracies in managing inventory. Based on several cases that include cost issues, the buildup of goods to the loss of consumers, there needs to be a system of inventory management of goods. In this study, the authors designed an inventory management system that suits the needs of Muslimah Hijab's retail business management system. This design includes the planning stage with the creation of a Use case and designing a system display that includes a stock menu of goods, an entrance goods menu, and an exit goods menu. This system is coupled with the development of software using PHP (Hypertext Preprocessor).
\end{abstract}

Keywords : System, Management Inventory, Retail, Website.

\section{PENDAHULUAN}

Bisnis retail merupakan salah satu bisnis yang kegiatan usahanya meliputi penjualan barang atau jasa secara langsung kepada konsumen akhir untuk penggunaan pribadi dan bukan untuk bisnis. Bisnis retail ini disebut juga usaha eceran sebab biasanya produk dijual dalam jumlah satuan serta target marketing dari bisnis retail ini ialah konsumen akhir yang membeli produk barang atau jasa untuk kegiatan konsumsi bukan untuk dijual kembali. Berdasarkan pernyataan Asosisasi Pengusaha retail Indonesia (APRINDO) bahwa beberapa tahun terakhir bisnis retail mengalami peningkatan yang tajam setiap tahunnya. Salah satu bisnis retail yang mengalami peningkatan tersebut ialah retail fashion. Dewasa ini retail fashion khususnya fashion hijab menjadi bisnis yang sangat potensial, dengan mayoritas masyarakat muslim maka hijab ini akan selalu dicari oleh masyarakat. Fashion Hijab tidak hanya menjadi sebuah kebutuhan bagi masyarakat muslim, melainkan telah menjadi tren-lifestyle kehidupan modern khususnya bagi kaum muda.

Prospek bisnis retail yang cukup menjamin ini tentunya akan mengakibatkan permintaan yang meningkat. Namun disamping itu, jumlah pesaing pun semakin menjamur. Berhubung bisnis retail ini kegiatannya hanya menjual kembali produk tanpa menambah nilai guna sehingga produk yang dijual biasanya memiliki kemiripan dengan produk lain. Oleh karena itu, untuk bersaing dan menjaga eksistensi, toko harus mampu menyediakan produk yang dicari oleh konsumen. Karena jika konsumen tidak menemukan barang yang dicari dengan alasan ketidaktersediaan persediaan maka akan mengurangi citra pada toko tersebut. Hal tersebut pula memungkinkan konsumen beralih pada toko lain.

Permasalahan tersebut menunjukan bahwasannya persediaan barang dagang ini menjadi masalah yang cukup krusial dalam operasional manajemen retail karena terkait erat dengan pengelolaan persediaan barang dagang. Selain itu, 
kurangnya kualitas pengelolaan persediaan dapat mengakibatkan penumpukan barang dagang yang biasanya terjadi karena pembelian persediaan dilakukan berdasarkan perkiraan atau ingatan saja tanpa melakukan perhitungan secara akurat. Hal ini tentunya akan merugikan bagi pemilik karena dapat menyebabkan penumpukan persediaan yang beresiko mengalami kerusakan barang dan tidak bisa ditukar atau dikembalikan pada supplier. Berdasarkan beberapa kasus yang meliputi masalah biaya, penumpukan barang hingga kehilangan konsumen, maka perlu adanya sistem manajemen persediaan barang.

Penerapan sistem manajemen persediaan barang dalam bisnis retail ini dapat meningkatkan kualitas pengelolaan persediaan barang dagang sehingga jumlah persediaan yang tersisa di gudang dapat diketahui secara akurat serta dapat meminimalisir kesalahan. Namun, sistem ini baru diterapkan dalam bisnis retail besar sedangkan mayoritas bisnis retail kecil dan menengah masil menggunakan manajemen persediaan secara konvensional. Alasan terbesar masih minimnya sistem manajemen persediaan berbasis teknologi ini dikarenakan biaya pembuatan aplikasi yang cukup mahal serta dengan pengoperasian aplikasi yang cukup rumit sehingga memerlukan keterampilan khusus. Oleh karena itu, Muslimah Hijab sebagai salah satu bisnis retail kecil merancang inovasi sistem manajemen persediaan yang tidak hanya canggih namun mudah dioperasikan sehingga dapat diterapkan dalam berbagai kalangan bisnis retail. Perancangan ini tentunya untuk menunjang manajemen persediaan yang berkualitas sehingga diharapkan bisnis retail kecil ini dapat meningkatkan efektivitas dan efisiensi dalam pengelolaan persediaan dan memiliki daya saing yang tinggi.

\section{TINJAUAN PUSTAKA}

\section{Sistem}

Sistem merupakan kumpulan unsur yang memiliki keterkaitan dan saling bekerja sama dalam satu kesatuan untuk mencapai suatu tujuan atau sasaran. Sejalan dengan Lani Sidharta yang mengemukakan bahwa sistem merupakan himpunan dari bagian yang saling berhubungan, yang bekerjasama dalam mencapai tujuan[10]. Sedangkan menurut Rusdiana \& Irfan, sistem adalah seperangkat unsur yang saling berhubungan dan saling memengaruhi dalam satu lingkungan lingkungan tertentu[1]. Contoh sebuah sistem adalah sistem Komputer, sebuah komputer tersusun dari unsur-unsur yang saling berkaitan seperti keyboard, CPU, monitor dan modem yang memiliki tujuan untuk mengolah data.

\section{Manajemen Persediaan}

Manajemen persediaan meliputi bagaimana organisasi dapat mengendalikan barang dalam kegiatan penerimaan, penyimpanan, pemeliharaan, dan penyaluran material dari hasil pengadaan serta penyimpanan persediaan. Perencanaan dan pengendalian persediaan merupakan suatu kegiatan yang penting dalam sebuah bisnis, sebab dengan adanya pengelolaan persediaan yang baik, maka tidak akan terjadi pemborosan biaya untuk persediaan dapat menghambat kegiatan operasional bisnis tersebut.[2]. Menurut Putra \& Hongdiyanto menyatakan bahwa manajemen persediaan merupakan kemampuan suatu perusahaan dalam mengatur dan mengelola setiap kebutuhan barang meliputi barang mentah, barang setengah jadi, ataupun barang jadi agar selalu tersedia baik dalam kondisi pasar yang stabil dan berfluktuasi[3].

\section{Bisnis Retail}

Berdasarkan pernyataan Levy dan Weitz "Retailing ialah satu rangkaian kegiatan bisnis untuk menambah nilai guna barang dan jasa yang dijual kepada konsumen untuk konsumsi pribadi atau rumah tangga"[4]. Sedangkan menurut Joko utomo mendefinisikan usaha eceran (retailing) merupakan semua kegiatan yang terlibat dalam penjualan barang atau jasa secara lagsung kepada konsumen akhir untuk penggunaan pribadi dan bukan bisnis. Jadi konsumen yang menjadi sasaran dari retailing adalah konsumen akhir yang membeli produk untuk dikonsumsi sendiri[5].

\section{Website}

Website merupakan jaringan komputer yang terdiri dari kumpulan situs yang berisi teks, grafik, suara dan animasi melalui HTTP (Hypertext transfer protocol). Menurut pendapat ahli, website ini diibaratkan sebuah rumah yang harus memiliki alamat tetap, terdapat bangunan secara fisiknya, serta ada isinya seperti peralatan atau perabotan yang memungkinkan seseorang dapat beraktivitas didalam rumah tersebut. Sama Halnya seperti website ini yang membutuhkan alamat berupa domain name, web hosting sebagai fisik bangunannya, dan tentunya desain serta aplikasi web sebagai isinya[6].

\section{PHP (Hypertext Preprocessor)}

Hypertext Preprocessor ialah salah satu bahasa pemograman berbasis web yang diterapkan pada sisi server. PHP ini berfungsi untuk membuat alur pada website. PHP dapat disisipkan diantara skrip-skrip bahasa HTML (kerangka website) dan arena bahasa server-side lainnya, dengan itu maka PHP akan dieksekusi secara langsung pada server. Sedangkan browser akan mengeksekusi halaman web tersebut melalui server yang kemudian akan menerima tampilan "hasil jadi" dalam bentuk HTML, sedangkan kode PHP itu sendiri tidak akan dapat terlihat[7]. 


\section{ANALISIS DAN PERANCANGAN}

1. Metodologi Penelitian

Dalam penelitian ini penulis menggunakan metodologi penelitian kuantitatif dengan metode pengembangan perangkat lunak menggunakan PHP (Hypertext Preprocessor). Adapun pengumpulan data yaitu diambil dari artikelartikel dari jurnal ilmiah yang terpercaya. Dalam penyusunan sistem manajemen persediaan ini meliputi perencanaan dan desain (gambaran umum website).

\section{Perencanaan Sistem}

Berdasarkan analisis kebutuhan dari Muslimah Hijab yang merupakan bisnis retail kecil ini, maka penulis membuat perancangan sistem usulan untuk menggambarkan interaksi antar pengguna terhadap sistem yang digambarkan melalui use case diagram. Use Case dalam penelitian ini melibatkan 2 yang berperan, yaitu Admin gudang yang berperan sebagai mengolah data barang, mengolah data pembelian serta penjualan dan terdapat Owner untuk memeriksa laporan persediaan barang.

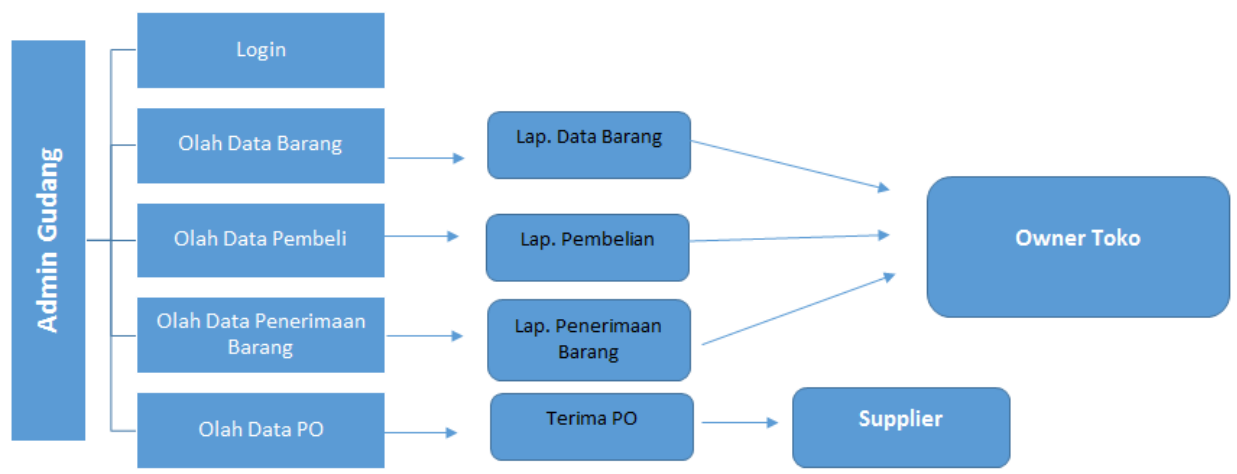

Gambar 1. Use Case Diagram

3. Gambaran Umum Sistem

Berikut merupakan tampilan aplikasi yang dihasilkan dari hasil perancangan sistem

a. Login

Tentunya untuk dapat mengakses aplikasi manajemen persediaan setiap aktor yang terlibat harus Login terlebih dahulu dengan memasukan email serta Password.

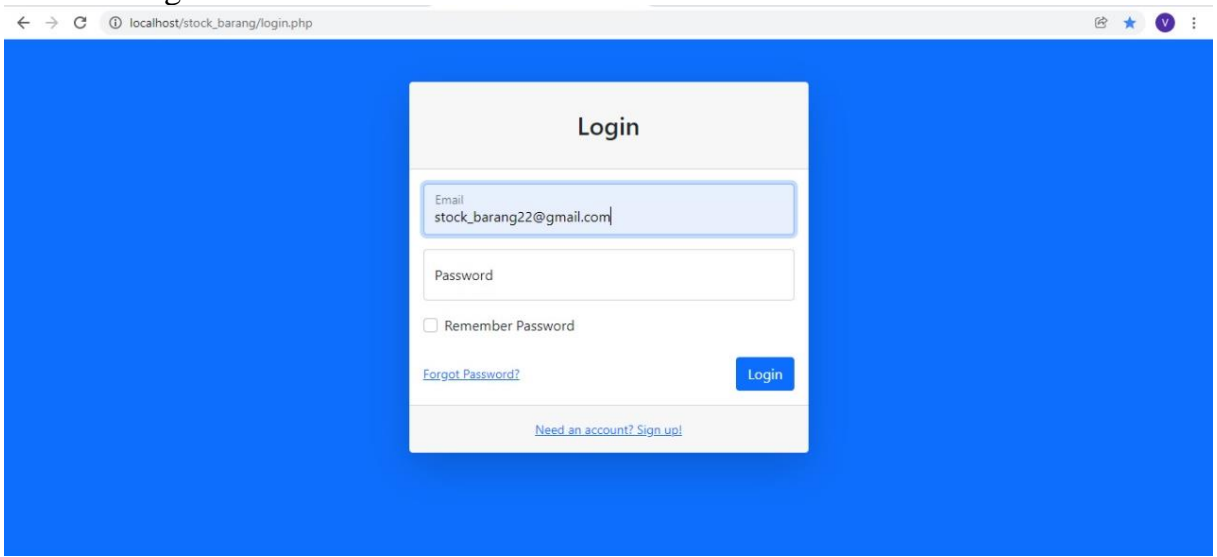

Gambar 2. Menu Login

b. Stock Barang

Pada Menu Stock Barang Admin gudang hanya dapat mengelola data barang yaitu input Nomor barang dan detil barang untuk kebutuhan informasi stock seperti nama barang, deskripsi dan stock yang tersedia. Persediaan barang dagang yang diinput ini hanya berupa persediaan awal atau ketika terdapat jenis persediaan persediaan baru. 

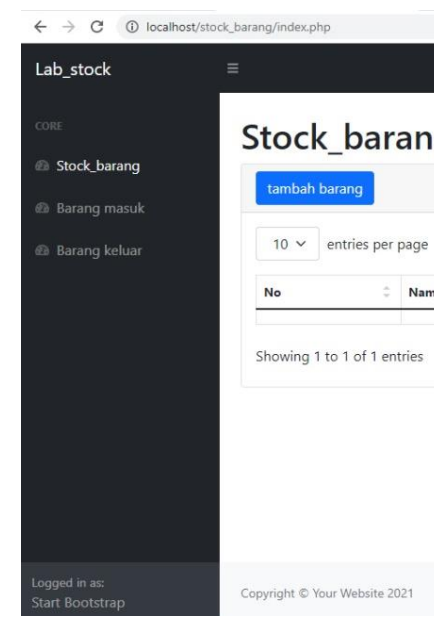

a.

Stock_barang

10 v

No $\quad$ Nama Barang $\quad$ Deskripsi $\quad$ Stock

showing 1 to 1 of 1 entries

Gambar 2. Menu Stock Barang

c. Barang Masuk

Pada menu Barang Masuk ditujukan untuk mengelola data pembelian barang yaitu input kode barang, harga dan kuantitas persediaan barang dagang yang dibeli. Jumlah barang yang tercatat pada menu ini akan secara otomatis tercatat pula di menu stock barang.

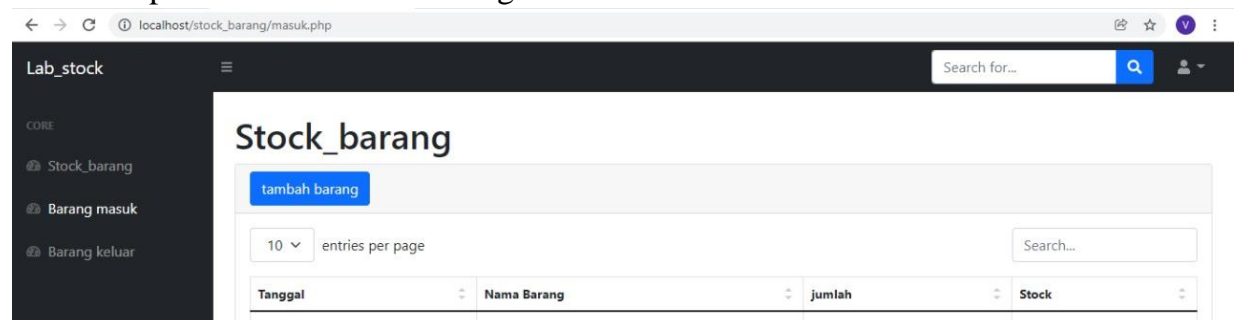

Showing 1 to 1 of 1 entries

Copyright @ Your Website 202

Gambar 3. Menu Barang Masuk

d. Barang Keluar

Menu Barang Keluar ditujukan untuk mengelola data penjualan barang yaitu dengan input kode barang dan kuantitas persediaan barang dagang yang terjual. Persediaan yang dicatat dalam menu ini akan secara otomatis mengurangi kuantitas persediaan pada menu stock barang.

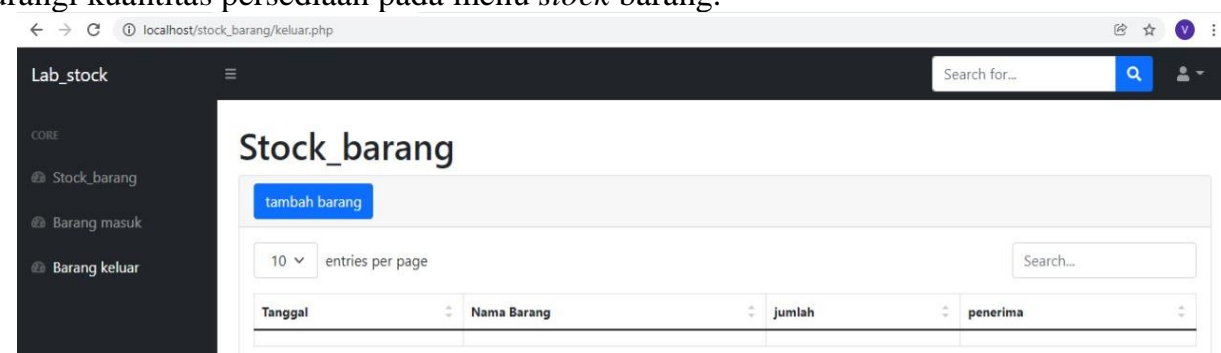

Showing 1 to 1 of 1 entries 


\section{KESIMPULAN}

Sistem Manajemen Persediaan yang dirancang ini melalui beberapa tahap diantaranya ialah tahapan perencanaan perancangan sistem dengan pembuatan Use case serta merancang tampilan menu sesuai dengan hasil analisis terhadap kebutuhan sistem manajemen bisnis retail Muslimah Hijab, meliputi menu stock barang, menu barang masuk untuk mencatat pembelian barang serta menu barang keluar untuk mencatat penjualan barang. Perancangan sistem manajemen persediaan barang dagang berbasis website ini diharapkan dapat bermanfaat khususnya bagi Muslimah Hijab dan umumnya untuk bisnis retail lainnya dalam meningkatkan kualitas manajemen persediaan secara lebih efektif dan efisien sehingga mampu menghasilkan informasi persediaan yang lebih akurat dan cepat. Adanya kemudahan mengakses dan sistem pencatatan yang sangat sederhana sehingga pencatatan tidak harus dilakukan oleh orang yang expert dibidang akuntansi saja, tentunya orang tanpa latar belakang pendidikan keuangan pun dapat mengoperasikannya.

\section{REFERENSI}

[1] Rusdiana, A., Irfan, M., \& Irfan, M. (2014). Sistem informasi manajemen. Bandung : Pustaka Setia.

[2] Meyliawati, M., \& Suprianto, E. (2016). Tinjauan Sistem Prosedur Pengeluaran Material C212 di gudang Manajemen Persdiaan PT X. INDPT, $6(1), 17-23$

[3] Putra, A. K., \& Hongdiyanto, C. (2015). Analisis Penerapan Manajemen Persediaan pada Perusahaan Goodwill. Jurnal Aplikasi Manajemen, 13(3), 423434

[4] Levy \& Weitz, 2001. Retailing Management, 4th edition. New York: Mc.GrawHill, Irwin.

[5] Tri Joko Utomo, "Fungsi dan Peran Bisnis retail dalam Saluran Pemasaran", Fokus Ekonomi, 1(Juni, 2009), 46

[6] Rozi, Zaenal A, dan SmitDev Comunity. (2016). Modern Web Design. Jakarta: PT Elex Media Komputindo.

[7] Haryana, K. S. (2015). Pengembangan Perangkat Lunak dengan Menggunakan PHP. Jurnal Computech \& Bisnis, 2(1), 1-2

[8] Indrianasari, E. (2017). Rancangan Sistem Informasi Manajemen Inventory Pada Toko Mutiara Sari di Sidoarjo. CALYPTRA, 6(1), 1203-1211

[9] Rosanti, N., \& Meilina, P. (2018). Penerapan Teknologi Informasi Untuk Manajemen Persediaan Barang \& Keuangan. Prosiding Semnastek. 3-

[10] Lani Sidharta. (1995). Pengantar Sistem Informasi Bisnis. Jakarta: PT. Elex Media Komputindo 